Volume 10, No.5, September - October 2021

International Journal of Advanced Trends in Computer Science and Engineering

Available Online at http://www.warse.org/IJATCSE/static/pdf/file/ijatcse151052021.pdf

https://doi.org/10.30534/ịatcse/2021/151052021

\title{
A Logical Framework for Scientific Research Projects based on Blockchain Technology
}

\author{
Mohamed Elbialy ${ }^{1}$, Dr. Mohamed Abd Elsalam ${ }^{2}$, Prof. Samir Abo El-Fotouh ${ }^{3}$ \\ ${ }^{1}$ Ministry of Higher Education and Scientific Research, Egypt, mohamed@elbialy.net \\ ${ }^{2}$ Business Information Systems Department Faculty of Commerce \& Business Administration, Helwan \\ University, Egypt, dr.m_abdelsalam@commerce.helwan.edu.eg \\ ${ }^{3}$ Information Systems, Faculty of Commerce, Mansoura University, Egypt, prof_samir@ hotmail.com
}

Received Date : August 05, 2021 Accepted Date : September 15, 2021 Published Date : October 06, 2021

\begin{abstract}
The Scientific research projects has encountered severe problems in procurements of supply for research projects in Egypt. Despite the huge number of scientific researches projects annually. The cost of scientific research projects is so high and it has a lot of elements in their supply chains. Due to this, it becomes almost impossible to keep track of each and every record in traditional ways. The lack of transparency and increased cost of projects lead to some of scientific researches not turn into a final product and facing many problems.

This paper proposed a logical framework for enhancing the supply of scientific research projects using Blockchain. by analyzing the previous works in Blockchain \& Smart Contract, Blockchain \& e-commerce, Blockchain \& Procurement, and Blockchain \& Tender. The researcher built the research point from this analyzing. Using Blockchain in Procurements and Blockchain in Tenders as a method for Build a Framework for effectively lead to increase security, minimize delays in paperwork and increase the transparency and quality assurance.
\end{abstract}

Key words: Blockchain, Smart Contracts, Procurement, e-commerce, Tender, Cryptocurrency.

\section{INTRODUCTION}

In today's world, we are awash in a flood of data. Across a broad range of application areas, data is being collected at unprecedented scale. Decisions that previously were based on guesswork, or on painstakingly constructed models of reality, can now be made based on the data itself [1].

The overall market is in front of a new technological change, where several markets need a technology that can speed up the different processes and bring more safety and transparency into the market [2].

Public procurement is a core function of government activities that catalyzes economic growth and development, if conducted efficiently and transparently. [3].
Despite the huge number of scientific researches projects annually. The cost of scientific research projects is so high and it has a lot of elements in their supply chains. Due to this, it becomes almost impossible to keep track of each and every record in traditional ways. The lack of transparency and increased cost of projects lead to some of scientific researches not turn into a final product and problems. blockchain technology has a high potential to significantly improve procurement systems, in particular, with respect to data integration across business functions. Thus, the infusion of blockchain technology causes a positive shift in the way organizations carry out procurement, thereby creating more possibilities for growth and expansion on a global scale. [3].

Egypt, The National Bank of Egypt has announced that it has joined the membership of one of the largest initiatives for the research and applications of the.Development strategy and vision of Egypt 2030:

Egypt is now providing all possible support to achieve a real and effective scientific renaissance that contributes to the development industry by linking scientific research with the development strategy and vision of Egypt 2030, and making full use of research projects in advancing the development process.

The government investments in the scientific research sector in 2016/2017 amounted to LE 12.375 billion in order to stimulate the public and private sectors and civil society institutions to participate in scientific research activities and the State is keen to support innovation and innovators.

Egypt has a national wealth of research staff in various disciplines. The scientific research index of the Academy of Scientific Research and Technology has announced that:

Number of researchers in Egypt in all sectors:

- 127.000researchers in Egypt

- 22.505 researchers in the research centers of the ministries.

- 100.391 researchers in public and private universities.

- 4.653 researchers in the private sector.

- 221 researchers in non-profit organizations. 


\section{RESEARCH BACKGROUND}

\subsection{Blockchain}

Blockchain is both the network and database, secure and integrate [4]. Blockchain can be used for any form of asset, including every area of finance, economics, and money [5]. In 2018, someone hiding behind the pseudonym Satoshi Nakamoto created Bitcoin, the first decentralized cryptocurrency operating without a central bank or authority. However, the true revolution seems to be its underlying technology blockchain [6].

Blockchain could be the most consequential development in information technology since the Internet [7].

\subsubsection{Types of blockchains}

Blockchains comes in many forms, but one of the fundamental aspects with blockchain is that there is always a network of nodes (computers/actors) participating in the network. A blockchain is often distinguished between three different types: private, public and a consortium. [8].

Table 1: Generalized Features Comparison: Public vs Private/Consortium Blockchain

\begin{tabular}{|l|l|l|}
\hline Characteristics & Public & Private/Consortium \\
\hline Access & $\begin{array}{l}\text { Open read/write access to } \\
\text { database }\end{array}$ & $\begin{array}{l}\text { Permission rean and/or } \\
\text { write access to database }\end{array}$ \\
\hline Speed & Slower & Faster \\
\hline Security & PoW/PoS & Pre-approved participants \\
\hline Identity & Anonymous/pseudonymous & Known identities \\
\hline
\end{tabular}

\section{- Public blockchain}

In a public blockchain anyone is allowed to participate, anyone can send transactions and participate in the consensus process. The ledger is publicly available to all participants, which means that everyone in the network has the same information at all times [9]. Public blockchain benefits from disintermediation, due to the architecture of peer-to-peer network were the central actor in the middle is removed. Most crypto currencies in the blockchain sphere are built as public blockchains, they draw the benefits of value transaction without going through a bank, and thereby have lower transaction costs.

Public blockchain Examples:

Bitcoin. Bitcoin is the most popular example of a concept intrinsically tied to blockchain technology. Bitcoin is a digital currency and online payment system in which encryption techniques are used to regulate the generation of units of currency and verify the transfer of funds, operating independently of a central bank [5].

\section{- Private blockchain}

In a private blockchain you need an invitation and a validation from the other participators in the network to be accepted as a part of the private blockchain. The user is typically restricted to only certain transactions and does not have access to transactions where the individual or organization is not involved. The rules for participation, consensus, and restrictions to the ledger may vary from each private blockchain [9].

Private blockchain Examples:

Hyperledger is an open source collaborative effort created to advance cross-industry blockchain technologies. It is a global collaboration, hosted by the Linux Foundation, including leaders in finance, banking, IoT, supply chain, manufacturing and technology [10].

\subsubsection{Consensus algorithms Types:}

\section{- Proof of Work (PoW)}

The most known type of consensus algorithm in relation to blockchain technology is proof of work, which is used in the cryptocurrency Bitcoin. "In proof of work, miners compete to add the next block (a set of transactions) in the chain by racing to solve a extremely difficult cryptographic puzzle..."[11].

A new block can be accepted by the network after being validated through mining. Miners can choose to mine any unverified blocks on the network by solving a puzzle and compete with one another until a winner emerges. If a miner is the first to find a hash that matches the current target, it broadcasts the block across the network to each node. Once the block passes the verification, each node adds this block to their own copy of the ledger. If another miner finds the hash faster, then the rest of miners will stop working on the current block and start the mining process for the next block [12].

\section{- Proof of Stake (PoS)}

The PoS algorithm aims to replace the existing way of achieving consensus in a distributed system; instead of solving the PoW, the node that generates a block has to provide proof that it has access to a certain amount of coins before being accepted by the network [13]. PoS (Proof of stake) is an energy-saving alternative to PoW. Miners in PoS have to prove the ownership of the amount of currency. It is believed that people with more currencies would be less likely to attack the network [14].

\section{- Practical Byzantine Fault Tolerance (PBFT)}

This consensus algorithm was developed to tolerate Byzantine faults, for instance, the arbitrary behavior of the node, joining and quitting the network at any time that usually occurs in a distributed system. This algorithm presents a state machine replication technique to cope with Byzantine faults [15].

\section{- Delegated Proof of Stake (DPoS)}

The major difference between PoS and DPoS is that PoS is a direct democratic process, while DPoS is representatively democratic - stakeholders elect delegates to generate and validate a block. With significantly fewer nodes to validate the block, the block can be confirmed quickly, meaning the transaction can be confirmed quickly [16]. 


\subsection{Smart Contracts}

Smart contracts (SCs) are small, event-triggered programs that run in a trustless environment on a decentralized P2P network [17].

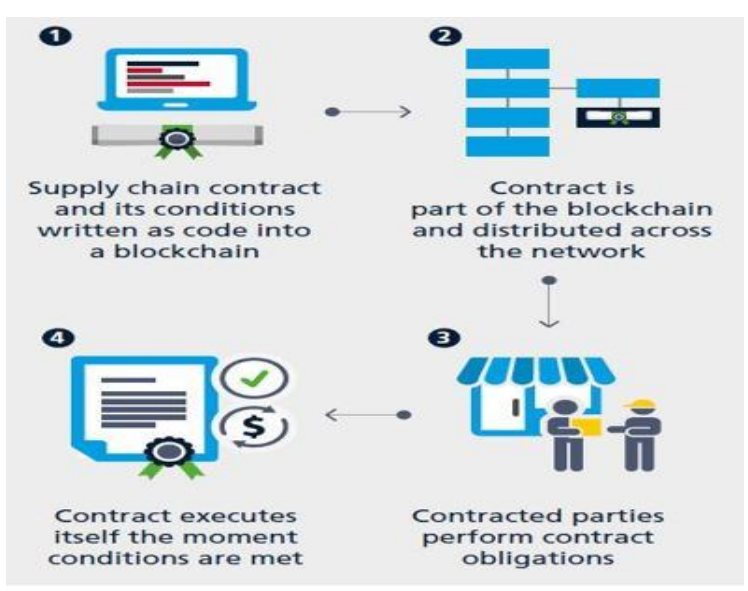

Figure 1: How smart contracts could work Source: Markus Kückelhaus, DHL, 2020

Banks and lawyers that are involved as third parties in regular contracts, can be seen as a function outdated with smart contracts. [5].

\subsubsection{Architecture of Smart Contracts}

To deploy a smart contract in Ethereum, a special creation transaction is executed. This introduces a contract to the blockchain. During this procedure, the contract is assigned a unique address and its code is uploaded to the blockchain. Once successfully created, a smart contract is identified by a contract address [18].

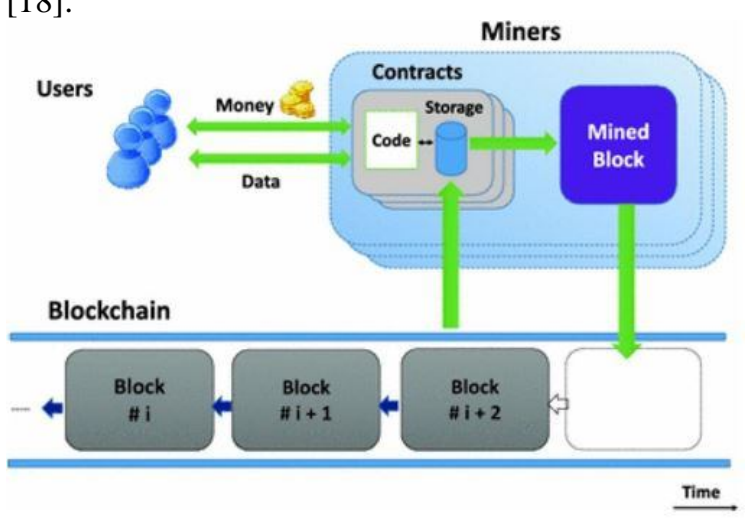

Figure 2: The smart contract system Source: K. Delmolino et al., 2016

Smart contracts are self-executable and self-verifying agents that cannot be changed once deployed in the blockchain. Smart contract checks to see if participants in a transaction comply with the rules predefined in the smart contract. If they do, the transaction is validated; if not, the transaction is rejected. Smart contracts can be used to transfer assets of considerable value. Hence, it is crucial that their implementation is secure and bug- free [19].

\subsubsection{Platforms of Smart Contracts}

Smart contracts can be developed and deployed in different blockchain platforms. Different platforms have different characteristics.

\section{- Ethereum.}

Ethereum is a public blockchain platform on which applications run exactly as programmed without any possibility of downtime, censorship, fraud or thirdparty interference [20]. It uses Ether crypto currency. The main idea of Ethereum is separation of contract layer and blockchain layer, so that it provides more flexible development environment than Bitcoins [21].

Ethereum deals mostly with financial issues such as money transfers and more complexity of code, it is worth full now to concentrate on automated deep learning models for efficient detection of SC vulnerabilities [22].

\section{- Hyperledger Fabric}

Hyperledger Fabric is a blockchain framework implementation which is hosted by Linux Foundation [23]. Hyperledger Fabric is open source permissioned blockchain that was introduced by IBM, frst as Hyperledger Fabric and then more recently, in 2017, IBM released Hyperledger Fabric v1.0 [24].

It is a platform for distributed ledger solutions, underpinned by a modular architecture delivering high degrees of confidentiality, resiliency, flexibility and scalability. It is designed to support pluggable implementations of different components, and accommodate the complexity and intricacies that exist across the economic ecosystem [25].

\section{RESEARCH REVIEWS}

A systematic review of the literature was conducted to assess a Framework for Enhancing the Supply of Scientific Research Projects Using Blockchain. This research focused on three concepts which help for answering the main research question, these concepts are blockchain \& Procurement, blockchain \& tender, blockchain \& e-commerce, Blockchain $\&$ Smart Contract and blockchain.

Literature resulted in an initial retrieval of 7157 relevant titles and abstracts of peer reviewed publications. The researcher selects the top 3 international publications for search on relevant studies, these publications are IEEE, Springer, and Science Direct. In addition, specific years was selected to search for relevant studies as 2020, 2019, 2018, 2017 and 2016. All retrieved articles were initially evaluated based on titles and abstracts to identify studies to be retained for further analysis based on full text appraisal.

The following table [3.1] represents the number of relevant studies for each concept. 
Table 2: Total of studies related of each concept

\begin{tabular}{|l|c|c|c|c|}
\hline \multicolumn{1}{|c}{ Concept } & IEEE & Springer & $\begin{array}{c}\text { Science } \\
\text { Direct }\end{array}$ & Total \\
\hline Blockchain & 1581 & 1735 & 2421 & 5737 \\
\hline Blockchain \& Smart Contract & 338 & 607 & 906 & 1851 \\
\hline Blockchain \& e-commerce & 5 & 190 & 571 & 766 \\
\hline Blockchain \& Procurement & 3 & 75 & 199 & 277 \\
\hline Blockchain \& Tender & 3 & 41 & 75 & 119 \\
\hline
\end{tabular}

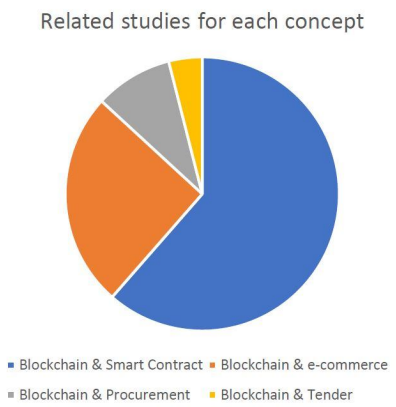

Figure 3: Comparison between the numbers of related studies for each concept.

\subsection{Blockchain}

There were huge studies that talking about Blockchain. 5737 is the number of relevant studies for Blockchain from 2016 to 2020 in the journals. Blockchain is the keyword used for searching on these studies. The table [3.1] shows the numbers of studies for specific journal across specific years.

Table 3: Studies related to Blockchain

\begin{tabular}{|c|c|c|c|c|c|}
\hline Journal & 2020 & 2019 & 2018 & 2017 & 2016 \\
\hline IEEE & 620 & 348 & 94 & 8 & 7 \\
\hline Springer & 831 & 430 & 322 & 115 & 37 \\
\hline Science Direct & 1375 & 735 & 236 & 61 & 14 \\
\hline
\end{tabular}

As you mention in above table, Blockchain is new revolution for technology. Therefor the number of related studies is enormous. The following figure summarize it.

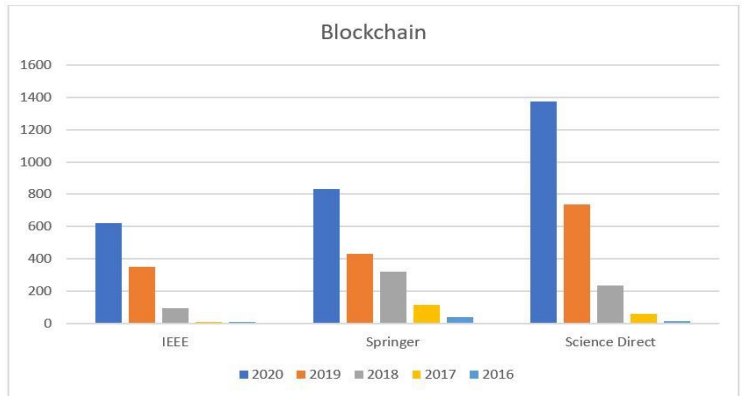

Figure 4: Number of related studies for Blockchain

The following section represents the most relevant studies to Blockchain. In addition, represents all approaches and technologies used to achieve Blockchain.

$\begin{array}{lcr}\text { RAFAEL } & \text { GENÉS DURÁN, DIANA } & \text { YARLEQUÉ- } \\ \text { RUESTA, } & \text { MARTA BELLÉS-MUÑOZ, ANTONIO }\end{array}$
JIMENEZ-VIGUER, AND JOSÉ L. MUÑOZ-TAPIA, (2020), An Architecture for Easy Onboarding and Key LifeCycle Management in Blockchain Applications, propose an architecture that simplifies and simplifies how users use decentralized applications without sacrificing the expected security. To achieve this goal, our engineering uses middleware. It allows us to separate the digital signatures required to pay blockchain fees from those required Authorization. This approach has the advantage of not forcing users to create wallets, buy cryptocurrencies, or protect their private keys. For these reasons, this model leads to improved traceability, enhanced security, increased transaction speed and reduced costs

HYE-YOUNG PAIK, XIWEI XU, H. M. N. DILUM BANDARA, SUNG UNE LEE, AND SIN KUANG LO, (2019), Analysis of Data Management in Blockchain-Based Systems: From Architecture to Governance. Analyze blockchain from the developer's point of view to highlight important concepts and considerations when integrating the blockchain into a larger software system as a data store. The work aims to increase the level of understanding of blockchain technology as a data warehousing and to promote a systematic approach in its application to large software systems by means of. First: Determine Common architectural layers of a typical software system with data stores and visualization of each layer in terms of the blockchain. Second, examine the status and flow of data in blockchain-based applications. Third: Explore the data management aspects of blockchain networks, especially as a distributed data store. Fourthly, Discuss blockchain data analytics and blockchain-enabled trusted data analytics. Finally, Studying data management problems in block chains in terms of privacy and quality assurance.

YONG YUAN AND FEI-YUE WANG, (2018), Blockchain and Cryptocurrencies: Model, Techniques, and Applications. Advances a systematic investigation into the blockchain and cryptocurrency. Relevant basic rationales and existing technical advantages and the potential ecosystems of Bitcoin and other cryptocurrencies discussed, a six-layer reference model of the blockchain. The proposed framework with a detailed description of each six layers. Potential applications of blockchain and cryptocurrency it is also eaten. The goal is to provide guidance and a reference for future research along this promising and important direction.

\subsection{Smart Contract \& Blockchain}

There were many studies that discuss Smart Contract. 1851 is the total number of pertinent studies for Smart Contract from 2016 to 2020 in the journals. Smart Contract \& Blockchain are the keywords used for searching on these studies. The table [3.3] shows the numbers of studies for specific journal throw specific years. 
Table 4: Studies related to Smart Contract \& Blockchain

\begin{tabular}{|c|c|c|c|c|c|}
\hline Journal & 2020 & 2019 & 2018 & 2017 & 2016 \\
\hline IEEE & 206 & 111 & 19 & 1 & 1 \\
\hline Springer & 288 & 135 & 138 & 32 & 14 \\
\hline Science Direct & 528 & 257 & 96 & 22 & 3 \\
\hline
\end{tabular}

As you see in higher table, Smart Contract is new revolution for technology. For these reason the number of related studies is enormous. The following figure summarize it.

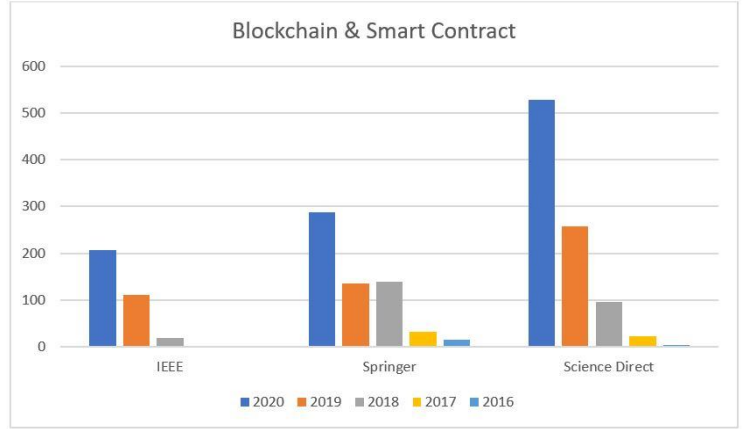

Figure 5: Number of related studies for Smart Contract \& Blockchain

The following part represents the most relevant studies to Smart Contract \& Blockchain. In addition, represents all approaches and technologies used to achieve Smart Contract.

THARAKA HEW, MIKA YLIANTTILA, MADHUSANKA LIYANAGE, (2020), Survey on blockchain based smart contracts: Applications. The research explores important applications that have already taken advantage of smart contracts. It also highlights the future potential of blockchain based smart contracts in the application perspective of decentralized and autonomous execution with the built-in transparency of blockchain-based smart contracts.

SHUANGKE WU, YANJIAO CHEN, MEMBER, QIAN WANG, MINGHUI LI, CONG WANG, AND XIANGYANG LUO, (2019), CReam: A Smart Contract Enabled Collusion-Resistant e-Auction, declared Cream. It is the first decentralized, collusion-resistant electronic auction system implemented with a smart contract on the blockchain. With a carefully designed smart auction contract, rational sellers and buyers are incentivized to act properly, thus transacting safely without trusted third party's dependent on decentralization. The auction mechanism relies on the smart contract to effectively overcome the collusion of bidders to form collusive alliances to manipulate the auction and reap unfair profits.

CONG NAM TRUONGA, MICHAEL SCHIMPEA, ULI BU"RGERB, HOLGER C. HESSEA, ANDREAS JOSSENA, (2018), Multi-Use of Stationary Battery Storage Systems with Blockchain Based Markets. proposed an auction market, where parts of the energy storage system and usage rights are auctioned off. Blockchain technology has been combined to develop a generic, low-cost concept that enables clear commitments between stakeholders due to the technical operation of the battery storage system. Smart contracts allow flexible sharing of the battery storage system and increase system utilization in the presence of forecast uncertainties.

\subsection{Blockchain \& E-commerce}

There are varieties of studies that investigate Blockchain \& E-commerce. 766 is the total number of relevant studies for Blockchain \& E-commerce from 2016 to 2020 in the previous journals. Blockchain \& E-commerce and Blockchain \& ecommerce are the keywords used for searching on these studies. The table [3.4] shows the numbers of studies that related to Blockchain \& E-commerce.

Table 5: Studies related to Blockchain \& E-commerce

\begin{tabular}{|c|c|c|c|c|c|}
\hline Journal & 2020 & 2019 & 2018 & 2017 & 2016 \\
\hline IEEE & 2 & 2 & 1 & 0 & 0 \\
\hline Springer & 110 & 33 & 24 & 15 & 8 \\
\hline Science Direct & 204 & 109 & 34 & 13 & 2 \\
\hline
\end{tabular}

Based on above table, Blockchain \& E-commerce is new trend for enhancing the Blockchain. For this way the number of related studies is limited. The following figure summarize it.

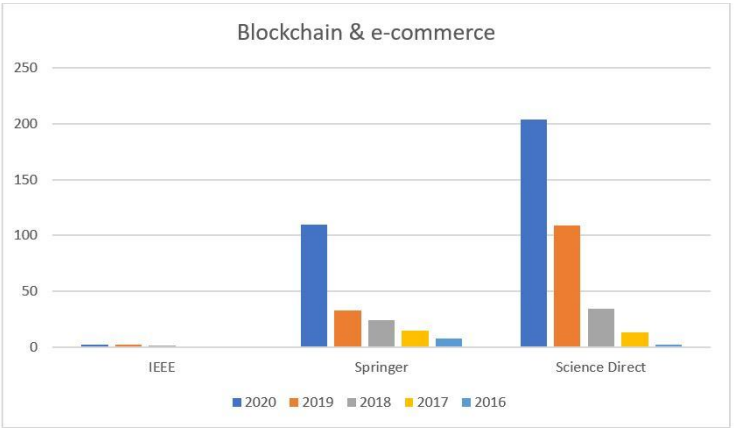

Figure 6: Number of related studies for Smart Contract \& E-commerce

The following section represents the most relevant studies to Blockchain \& E-commerce. In addition, represents all approaches and technologies used to achieve Blockchain \& E-commerce.

MING LIA,B, SAIJUN SHAOC, QIWEN YED, GANGYAN XUE,F, GEORGE Q. HUANGG, (2020), Proposed a Blockchain-enabled logistics finance execution platform for capital constrained E-commerce retail. Developed Blockchain Powered Logistics Finance Execution Platform (BCLFEP) as an end-to-end solution to facilitate eretail commerce. Then propose a multi-layered architecture for organizing and managing resources, workflows, and decisions based on (OOM). Smart Contract (HFSM-SC) is designed to connect and coordinate with all types of agents for LF operations throughout their lifecycle. Moreover, the blockchain is integrated Using proxy technology to build a blockchain-enabled multi-agent system (BcMAS), providing 
reliable Runtime environment for smart contract implementation more autonomously and efficiently.

CHUNCHI LIU, YINHAO XIAO, VISHESH JAVANGULA, QIN HU , SHENGLING WANG , MEMBER, AND XIUZHEN CHENG, (2019), proposed NormaChain, the standalone blockchain based transaction settlement system for Internet of Things based e-commerce. The proposed designing of a three layer private blockchain network, in order to increase the transaction efficiency and scalability of the system through a searchable public key crypto system decentralized public The key is encrypted using the Keyword Search Scheme (PEKS), thus Illegal and criminal transactions are detected and crime traceability is realized. It eliminates the dependence of a central authority and instead extends it to a fully decentralized system Governance, which distributes supervisory authority equally between all parties. The results show that the average transactions per second on IoT devices is 113, and the supervision accuracy is $100 \%$ at the appropriate target.

HAYA R. HASAN AND KHALED SALAH, (2018), proposed a framework using the Ethereum Blockchain to create a decentralized PoD system that ensures accountability, auditability and integrity between parties. The solution uses Ethereum Smart contracts to prove delivery of a shipped commodity between the seller and the buyer regardless of the number of intermediate carriers needed by using a double deposit guarantee and making sure that each entity gets its share of the ether upon successful delivery. The arbitration mechanism is also incorporated in the event that a dispute arises during the shipping process between the parties. Estimates of the cost of consuming ether gas in transactions between the parties are also given.

\subsection{Blockchain \& Procurements}

There are little of studies that investigate Blockchain \& Procurements. 277 is the total number of relevant studies for Blockchain \& Procurements from 2016 to 2020 in the previous journals. Blockchain \& Procurements is the keywords used for searching on these studies. The table [3.5] shows the numbers of studies that related to Blockchain \& Procurements.

Table 6: Studies related to Blockchain \& Procurements

\begin{tabular}{|c|c|c|c|c|c|}
\hline Journal & 2020 & 2019 & 2018 & 2017 & 2016 \\
\hline IEEE & 3 & 0 & 0 & 0 & 0 \\
\hline Springer & 46 & 16 & 9 & 4 & 0 \\
\hline Science Direct & 110 & 65 & 18 & 5 & 1 \\
\hline
\end{tabular}

As you show in above table, Blockchain \& Procurements is generation for the Blockchain. Therefore, the number of related studies is increased. The following figure summarize it.

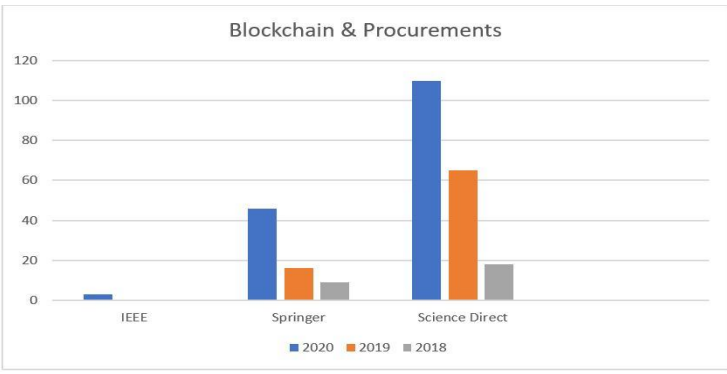

Figure 7: Number of related studies for Blockchain \& Procurements

The following part represents the relevant studies to Blockchain \& Procurements. furthermore, declares all aspects and technologies used to implement Blockchain \& Procurements.

ILHAAM A. OMAR, HAYA R. HASAN, RAJA JAYARAMAN, KHALED SALAH, MOHAMMED OMAR, (2020), Implementing decentralized auctions using blockchain smart contracts. Propose a general framework for decentralized auctions using Blockchain through three steps Firstly, smart contracts on the Ethereum network to track and track bids, Secondly, decentralized storage systems for uploading bid-related documents and finally, a trusted timer that acts as a gateway between the smart contract and external data feeds. In addition to developing detailed algorithms that define the working principles of the smart contract for the auction process. Plus, a detailed solution cost analysis to prove the economic viability of online auctions.

NOE ELISA, LONGZHI YANG, FEI CHAO, AND YI CAO, (2019), proposed a framework of blockchain-based secure and privacy preserving E-government system. A framework proposes a peer-to-peer (p2p) decentralized egovernment system using blockchain technology and storing outgoing data and new data in the form of blocks distributed across the network in a verifiable and immutable manner that can ensure information security and privacy while at the same time increasing the trust of public sectors. In addition, a prototype of the proposed system is presented, supported by both theoretical and qualitative analysis, taking into account the security and privacy implications of such a system.

ADEGBOYEGA OJO AND SAMUEL ADEBAYO, (2017), declared a Blockchain as a Next Generation Government Information Infrastructure: A Review of Initiatives in D5 Countries. Providing background information on new technology and reviewing blockchain technology initiatives in D5 countries including the United Kingdom, United States and Estonia and concluding with recommendations to policy makers on emerging governance issues that require investigation in order to realize the full potential of blockchain innovation in the public administration and government sphere. 


\subsection{Blockchain \& Tenders}

There are a small of researches that explore Blockchain \& Tenders. 119 is the total number of pertinent researches for Blockchain \& Tenders from 2016 to 2020 in the previous journals. Blockchain \& Tenders is the keywords used for searching on these researches. The table [3.6] shows the numbers of researches that concerned to Blockchain \& Tenders.

Table 7: Studies related to Blockchain \& Tenders

\begin{tabular}{|c|c|c|c|c|c|}
\hline Journal & 2020 & 2019 & 2018 & 2017 & 2016 \\
\hline IEEE & 1 & 2 & 0 & 0 & 0 \\
\hline Springer & 23 & 7 & 8 & 1 & 2 \\
\hline Science Direct & 36 & 22 & 11 & 5 & 1 \\
\hline
\end{tabular}

As you see in upper table, Blockchain \& Tenders is a new trend for enhancing the Blockchain. For these reason, the number of concerned researches is increased. The following figure describe that.

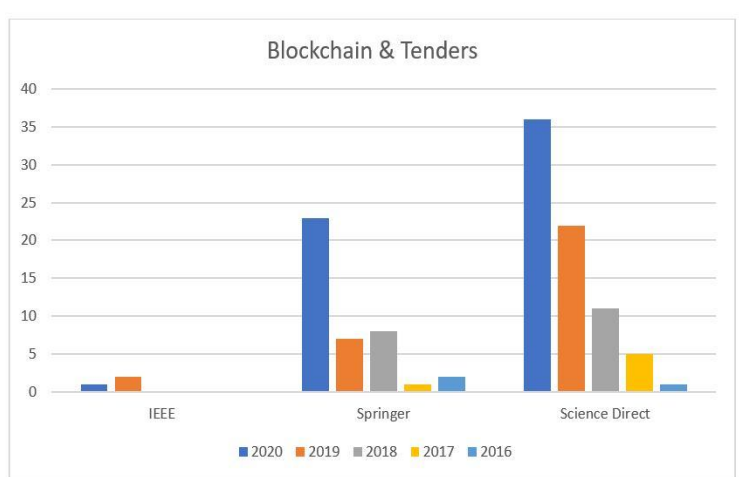

Figure 8: Number of related studies for Blockchain \& Tenders

The following section explains the concerned 'researches to Blockchain \& Tenders. furthermore, declare all aspects and technologies used to implement Blockchain \& Tenders.

PRANAMYA JAIN, SIDDHESH GANGAN, SIDDHESH RANE, YASH JAIN, AND DHIREN PATEL, (2020), Tenders 2.0 - A Stake-Based Blockchain Solution for Tender Procurement System. Propose a Bid Procurement System using secure, fair and reliable blockchain technology. It can manage the entire bidding process transparently and conduct an unbiased bid evaluation process with a decentralized system that makes records immutable, facilitating secure exchange of digital currency in deals and transactions. Every member of the blockchain network has access to the latest version of the encrypted ledger.

VIKAS HASSIJA, VINAY CHAMOLA, DARA NANDA GOPALA KRISHNA, NEERAJ KUMAR AND MOHSEN GUIZANI, (2020), A Blockchain and Edge-ComputingBased Secure Framework for Government Tender
Allocation. Presented a secure and transparent framework for government tenders that use the blockchain. Blockchain is used as a secure tool and an immutable data structure for storing government records that are highly vulnerable to tampering. This work aims to create a transparent and secure edge computing infrastructure for the workflow of government tenders to implement plans and policies by limiting human oversight so as to overcome attempts by various competitors to eavesdrop to win the bid. and to overcome the bribery that corrupt government officials take to pass a tender in favor of a particular third party.

LI LI, JIAYONG LIU, PENG JIA, (2019), SecTEP: Enabling secure tender evaluation with sealed prices and quality evaluation in procurement bidding systems over blockchain. Propose SecTEP wich is a secure and quality assessment method in bidding systems across the blockchain. SecTEP takes into account not only the bid price, but also the quality of the supplier, while providing protection and privacy of bids and evaluation results. SecTEP is built with cryptographic tools that check bid prices, compare bid prices, aggregate Quality Score and announce the winner on cryptographic values. Blockchain technology is used to ensure transparency.

\section{LOGICAL FrAMEWORK}

All The Logical Framework Approach was developed in 1969.

The Logical Framework Approach (LFA) is a management tool mainly used in the design, monitoring and evaluation of international development projects.

The Logical Framework takes the form of a four $\mathrm{x}$ four project table. The four rows are used to describe four different types of events that take place as a project is implemented: the project Activities, Outputs, Purpose and Goal. The first column is used to provide a Narrative description of the event. The second column lists one or more Objectively Verifiable Indicators (OVIs) of these events taking place. The third column describes the Means of Verification (MoV) where information will be available on the OVIs, and the fourth column lists the Assumptions.

Table 8: Proposed Logical Framework Part 1

\begin{tabular}{|l|l|l|l|}
\hline \multicolumn{1}{|c|}{ Activity description } & \multicolumn{1}{|c|}{$\begin{array}{c}\text { Performance } \\
\text { Indicators }\end{array}$} & \multicolumn{1}{|c|}{$\begin{array}{c}\text { Means of } \\
\text { Verification }\end{array}$} & \multicolumn{1}{c|}{$\begin{array}{c}\text { Risks and } \\
\text { Assumptions }\end{array}$} \\
\hline $\begin{array}{l}\text { Goal: } \\
\text { Supply of Scientific } \\
\text { Research Projects Using } \\
\text { Blockchain. }\end{array}$ & $\begin{array}{l}\text { Increase the percentage of } \\
\text { securing a Transactions } \\
\text { from attacks }\end{array}$ & $\begin{array}{l}\text { Rate of securing } \\
\text { System }\end{array}$ & Types of the systems \\
\hline $\begin{array}{l}\text { Purpose: } \\
\begin{array}{l}\text { Implementation steps to A } \\
\text { Framework for Enhancing } \\
\text { the Supply of Scientific } \\
\text { Research Projects Using } \\
\text { Blockchain }\end{array}\end{array}$ & $\begin{array}{l}\text { decreased rate of hacked } \\
\text { transactions Scientific } \\
\text { Research Projects }\end{array}$ & $\begin{array}{l}\text { Continuous scan of } \\
\text { the System } \\
\text { Vulnerabilities }\end{array}$ & $\begin{array}{l}\text { many of types for attack } \\
\text { System methods. }\end{array}$ \\
\hline $\begin{array}{l}\text { Outputs: } \\
\text { Rationalization of } \\
\text { government spending }\end{array}$ & $\begin{array}{l}\text { Low rate of the incidence } \\
\text { attacks on the platform of } \\
\text { Research Projects }\end{array}$ & $\begin{array}{l}\text { Measuring the rate of } \\
\text { attack the System }\end{array}$ & $\begin{array}{l}\text { web developer not aware } \\
\text { enough about the } \\
\text { methods of protection }\end{array}$ \\
\hline
\end{tabular}


Table 9: Proposed Logical Framework Part 2

\begin{tabular}{|c|c|c|c|}
\hline Activity description & $\begin{array}{l}\text { Performance } \\
\text { Indicators }\end{array}$ & $\begin{array}{c}\text { Means of } \\
\text { Verification }\end{array}$ & $\begin{array}{c}\text { Risks and } \\
\text { Assumptions }\end{array}$ \\
\hline $\begin{array}{l}\text { Activities: } \\
\text { - Declare the traditional } \\
\text { system } \\
\text { - Create Smart } \\
\text { Contracts } \\
\text { - Deploy Science Coin } \\
\text { - Deploy Blockchain on } \\
\text { network } \\
\text { - Make wallet for each } \\
\text { node on blockchain } \\
\text { - Apply Science Coin } \\
\text { for Transitions } \\
\text { - Mining Fee } \\
\text { - Rewards Transactions }\end{array}$ & $\begin{array}{l}\text { - Steps to using a } \\
\text { Framework for } \\
\text { Enhancing the Supply } \\
\text { of Scientific Research } \\
\text { Projects Using } \\
\text { Blockchain Technology } \\
\text { clearly. }\end{array}$ & $\begin{array}{l}\text { - Knowledge of } \\
\circ \text { Admin } \\
\circ \text { Researcher } \\
\circ \text { Supplier } \\
\text { - System attacks } \\
\text { rate }\end{array}$ & $\begin{array}{l}\text { - The conditions in } \\
\text { smart contracts by law } \\
\text { experts in the field of } \\
\text { System security not } \\
\text { enough } \\
\text { - Training not enough }\end{array}$ \\
\hline
\end{tabular}

4.1 Goal, Purpose, Outputs and Activities:

The goal of this logical framework was to build A Logical Framework for Scientific Research Projects based on Blockchain Technology Reviews and the output from it to Rationalize of government spending and that includes many activities in the following:

- Declare the traditional system.

- Create Smart Contracts.

- Deploy Science Coin.

- Deploy Blockchain on network.

- Make wallet for each node on blockchain.

- Apply Science Coin for Transitions Mining Fee.

- Rewards Transactions

4.2 Performance Indicators

Performance Indicators can be check by the following:

- Increase the percentage of securing a Transactions from attacks.

- Decreased rate of hacked transactions Scientific Research Projects.

- Low rate of the incidence attacks on the platform of Research Projects.

- Steps to using a Framework for Enhancing the Supply of Scientific Research Projects Using Blockchain Technology clearly.

\subsection{Means and Verification}

For verification for the logical framework must be enough the following items:

- Rate of securing System.

- Continuous scan of the System Vulnerabilities.

- Measuring the rate of attack the System

- System attacks rate

- Knowledge of

- Admin

- Researcher

- Supplier

\subsection{Risks and Assumptions}

The logical framework may face some risks and assumptions at the following:

- Variety types of the systems.

- Many of types for attack System methods.
- Web developer not aware enough about the methods of protection.

- The conditions in smart contracts by law experts in the field of System security not enough.

- Training not enough.

\section{Conclusions}

By analyzing the previous works in Blockchain \& Smart Contract, Blockchain \& e-commerce, Blockchain \& Procurement, and Blockchain \& Tender. The researcher built the research point from this analyzing. Using Blockchain in Procurements and Blockchain in Tenders as a method for Build a Framework for Enhancing the Supply of Scientific Research Projects Using Blockchain to rationalization of government spending and decrease delays in the results of research projects. Finally, the integration between the methods proposed in the logical framework increase the performance and improving the process to enhance the solutions and increase the security.

\section{REFERENCES}

[1] Ravi Shukla, Audit and Validation Testing for Big Data Applications, STC 17th Annual International Software Testing Conference, 2017

[2] Don Tapscott \& Alex Tapscott, Blockchain Revolution: How the Technology Behind Bitcoin Is Changing Money, Business, and the World, Book, 2018

[3] Temofe Isaac Akaba, Alex Norta, Chibuzor Udokwu and Dirk Draheim, A Framework for the Adoption of Blockchain-Based e-Procurement Systems in the Public Sector a Case Study of Nigeria, Springer, M. Hattingh et al. (Eds.): I3E 2020, LNCS 12066, pp. $3-$ 14, 2020.

[4] DTCC, Embracing Disruption - Tapping the Potential of Distributed Ledgers to Improve the Post-Trade Landscape, 41, 2016

[5] Swan, M, Blockchain. 1st edition, Available at: http://book.itep.ru/depository/blockchain/blockchainby-melanie-swan.pdf, 2016

[6] Fyrigou-Koulouri, Blockchain Technology: An Interconnected Legal Framework for an Interconnected System, Journal of Law, Technology \& the Internet, Vol. 9, 2018

[7] Kevin Werbach, Trust but Verify: Why The Blockchain Needs The Law, Berkeley Technology Law Journal, Vol. 33 Issue 2, 2018

[8] Drescher, Blockchain Basics A Non-Technical Introduction in 25 Steps, book p.33, 2017

[9] Jayachandran, $P$, The difference between public and private blockchain, Retrieved from https://www.ibm.com/blogs/blockchain/2017/05/thedifference-between-public-and-private-blockchain/, 2017 
[10] Vitalik Buterin, A Next Generation Smart Contract \& Decentralized Application Platform, Ethereum White Paper, 2016

[11] Castor, A guide to blockchain consensus protocols, https://www.coindesk.com/markets/2017/03/04/ashort-guide-to-blockchain-consensus-protocols, 2017

[12] Rui Zhang, Rui Xue, Ling Liu, Security and Privacy on Blockchain, ACM Computing Surveys, Vol. 1, No. 1, Article, 2019

[13] Pavel Vasin, BlackCoinąírs Proof-of-Stake Protocol v2, 2018

[14] Zibin Zheng, Shaoan Xie, Hongning Dai, Xiangping Chen, and Huaimin Wang, An Overview of Blockchain Technology:Architecture, Consensus, and Future Trends, IEEE 6th International Congress on Big Data, 2017

[15] Miguel Castro and Barbara Liskov, Practical Byzantine Fault Tolerance, Third Symposium on Operating Systems Design and Implementation, New Orleans, USA, February 1999

[16] Qian Hua, Biwei Yanb, Yubing Hana, Jiguo Yu, An Improved Delegated Proof of Stake Consensus Algorithm, International Conference on Identification, Information and Knowledge in the internet of Things, 2020

[17] Monika Di Angelo, Gernot Salzer, Characterizing Types of Smart Contracts in the Ethereum Landscape, Conference Paper, DOI: 10.1007/978-3030-54455-3_28, August 2020

[18] Maximilian Wöhrer and Uwe Zdun, Smart Contracts: Security Patterns in the Ethereum Ecosystem and Solidity, IWBOSE, Campobasso, Italy, 978-1-53865986-1/18 , IEEE, 2018

[19] Shermin, Voshmgir, Disrupting governance with blockchains and smart contracts, briefings in entrepreneurial finance Jounal - Vol. 26, 2017

[20] Ethereum portal, ethereum.org

[21] K. Lakshmi Narayana, K. Sathiyamurthy, Automation and smart materials in detecting smart contracts vulnerabilities in Blockchain using deep learning, International Virtual Conference on Sustainable Materials, 2021

[22] Wesley Joon-Wie Tann, Xing Jie Han, Sourav Sen Gupta, and Yew-Soon Ong. Towards Safer Smart Contracts: A Sequence Learning Approach to Detecting Security Threats, In Proceedings of ACM Conference '19, 2019

[23] Hyperledger Fabric, https://github.com/hyperledger

[24] Hyperledger Fabric v0.6 Project, https://github.com/hyperledger/fabric/tree/release-1.0

[25] Maher Alharby, Aad van Moorsel, Blockchain-based Smart Contracts: A Systematic Mapping Study, Fourth International Conference on Computer Science and Information Technology, CSIT-2017

[26] THARUN P, SHAHRUKH PARVEZ R, Smart Grid Local Energy Trading Based Crypto Token Using Blockchain, International Journal of Advanced Trends in Computer Science and Engineering, Volume 10, No.3, May - June 2021

[27] Fyrigou-Koulouri, Blockchain Technology: AnInterconnected Legal Framework for An Interconnected System, Journal of Law, Technology \& the Internet, Vol. 9, 2018

[28] Kevin Werbach, Trust, But Verify: Why The Blockchain Needs The Law, Berkeley Technology Law Journal, Vol. 33 Issue 2, 2018

[29] Drescher, Blockchain Basics A Non-Technical Introduction in 25 Steps, book p.33, 2017

[30] S. H. Spencer Compton, Blockchain Technology and its Applicability to the Practice of Real Estate Law, National Commercial Services Division of First American Title Insurance Company, 2017

[31] Denis Corluka, Blockchain - A new technology that will transform the real estate market, Master's Thesis, Department of Real Estate \& Construction Management, University of Stockholm, 2017

[32] Erik Hillbom, \& Tobias Tillstrom, Applications of smart-contracts and smart-property utilizing blockchains, Master's Thesis, Department of Computer Science and Engineering, University of Gothenburg, 2016

[33] Don Tapscott \& Alex Tapscott, Blockchain Revolution: How the Technology Behind Bitcoin Is Changing Money, Business, and the World, Book, 2016

[34] DLT, B The future of financial infrastructure: An ambitious look at how blockchain can reshape financial services, World Economic Forum, 2016

[35] Pinna, A., \&Ruttenberg, W, Distributed Ledger Technologies in Securities Post-Trading Revolution or Evolution, ECB Occasional Paper, (172), 2016

[36] Marr, B, Big Data in Practice: How 45 Successful Companies used Big Data Analytics to Deliver Extraordinary Results, John Wiley \& Sons Ltd, United Kingdom, 2016

[37] G. Dhanalakshmi, B. Bhavethra, Muppa Keerthi Chowdary ,S. Keerthana, Securing Academic Record using Blockchain with Hyper ledger Fabric, International Journal of Advanced Trends in Computer Science and Engineering, Volume 10, No.3, May June 202 